\title{
Tuberculin conversion and abnormal chest radiograph in an infant
}

\author{
K. Magdorf*, M. Ertel*, A. Grassot**, U. Wahn*
}

A 15 month old girl, who had not received bacille Calmette-Guérin (BCG) vaccine, and who had no known exposure to tuberculosis, was hospitalized because of Salmonella enteritis. The child also suffered from persistent coughing. The primary routine Mantoux skin test with 100 tuberculin units (TU) was remarkably positive (20 mm induration) for the first time, so that tuberculin conversion was defined. Therefore, the child was presented to our out-patient department and a radiographic examination was performed (fig. 1). Breathing and percussion sound were reduced in the basal area of the right lung. The child had no fever and her clinical status was normal. There were no indications of foreign body aspiration. The child was admitted for further examination and bronchoscopy.

The laboratory findings were: erythrocyte sedimentation rate $(\mathrm{ESR}) 8 / 30 \mathrm{~mm} \cdot \mathrm{h}^{-1}$; C-reactive protein (CRP) below the detection limit. The blood count showed a slight leucocytosis of $15.8 \times 10^{9}$ cells $\cdot \mathrm{L}^{-1}$. Immunoglobulins in serum were normal. A Mantoux test with $1 \mathrm{TU}$ showed a positive reaction of $8 \mathrm{~mm}$ induration. Three samples of gastric juice were microscopically negative for mycobacteria. Bronchoscopy showed total occlusion of the bronchus intermedius due to perforation of lymph nodes. There was no microscopic evidence of mycobacteria in either the bronchial secretion or lymph node material. The bronchus intermedius was recanalized during the same session.

Due to the tuberculin conversion and abnormal radiographic image, as well as the bronchoscopic findings (macroscopic: necrotic lymph node material; histological: epithelioid cell granulomatosis), a primary tuberculosis was initially diagnosed, despite lack of microscopic evidence of tuberculosis bacteria. Combined antituberculotic chemotherapy (isoniazid, rifampin, pyrazinamide) was initiated, which was continued after discharge.

Although there were no clinical symptoms, findings of a control radiographic examination 6 weeks later became worse.

*Division of Pediatric Pneumology and Immunology, Humboldt University and **Dept of Radiology, Zehlendorf Hospital/Chest Clinic Heckeshorn, Berlin, Germany. a)

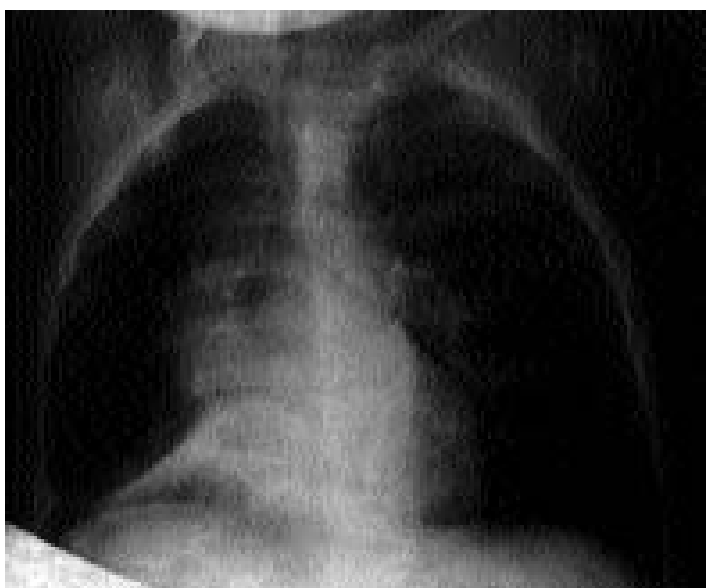

b)

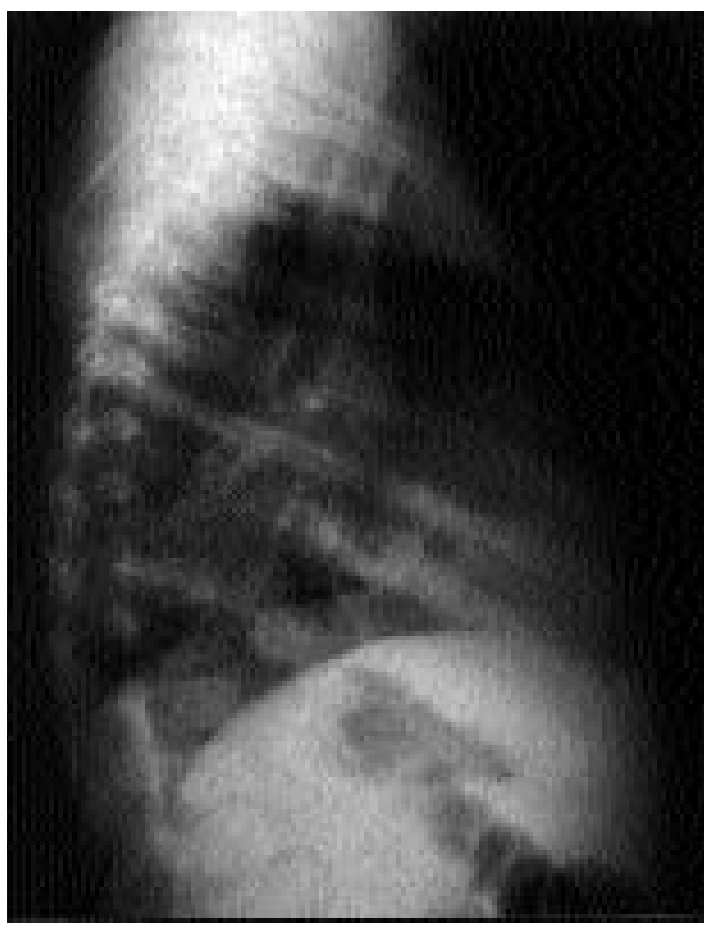

Fig. 1. - Chest-radiograph on admission: a) posterioranterior view; b) lateral view.

BEFORE TURNING THE PAGE: INTERPRET THE CHEST RADIOGRAPH AND SUGGEST A DIAGNOSIS. 




Fig. 2. - Chest radiograph after one year of treatment.

The chest radiograph on admission (fig. 1) showed marked enlargement of the right hilus as well as displacement of the mediastinum, trachea and main bronchi. Additionally, an opacity of the middle lobe and parts of the right lower lobe were observed, indicating atelectasis of both lobes.

After 6 weeks cultivation, the lymph node material obtained during the bronchoscopy revealed a strain of $M$. avium. In combination with the worsening radiographic results, the diagnosis of a primary pulmonary disease caused by $M$. avium infection was conclusive.

\section{DIAGNOSIS: "Primary pulmonary disease caused by M. avium infection"}

The strain of $M$. avium was resistant to all first choice antituberculotic agents. Sensitivity could only be demonstrated to prothionamide and clarithromycin. Treatment was modified accordingly: riframpin was continued, isoniazid and pyrazinamide were replaced by protionamide and clarithomycin.

Intense immunological investigation showed no signs of an immunodeficiency syndrome. Human immunodeficiency virus (HIV) serology was negative.

Another bronchoscopy was carried out 4 months after diagnosis. This time M. avium could not be demonstrated either microscopically or in culture. No granulations or stenosis were seen in the bronchial lumen. After 1 year of treatment and mainly normalized radiographic findings (fig. 2), chemotherapy was completed. The followup lasted for 2 years. During this time, there was no sign of relapse.

\section{Discussion}

Cervical lymphadenopathies caused by mycobacteria other than tuberculosis (MOTT) bacilli are not rare, but pulmonary diseases have seldom been reported in immunocompetent children $[1,2]$. Discontinuation of mass BCG vaccination may have had an effect on the rate of infection with MOTT [3]. In any case, the possibility of MOTT infection must be taken into consideration, especially if chemotherapy effects are insufficient.
Tuberculin skin-testing does not allow reliable differentiation between infections with $M$. tuberculosis or MOTT. A recent study has revealed a considerable portion of possible cross-reactions in tuberculin skin-testing with MOTT infection, as well as in sensitin (MOTT-purified protein derivative (PPD)) skin-testing with $M$. tuberculosis infection [4].

MOTT are found in the soil, hose dust and water, and are probably inhaled or ingested [5]. There is no evidence for person-to-person transmission of these organisms [6]. The natural course of infection is uncertain. MOTT does not usually cause severe disease in healthy children, only in patients with chronic pulmonary disease (e.g. cystic fibrosis) or immunodeficient patients (e.g. chronic granulomatous disease or HIV infection) [7-9]. In the present case, however, no immunodeficiency syndrome or other underlying disease was found.

Endoscopic, radiological and clinical findings of the reported case are similar to those of tuberculosis. Only cultural bacteriological evidence allows an exact differential diagnosis between $M$. tuberculosis and MOTT. However, the result cannot be achieved before 4-6 weeks in a conventional bacteriological investigation. Recent molecular approaches (e.g. polymerase chain reaction (PCR)) could probably suggested the final diagnosis earlier [10].

There are no evaluated modes of treatment for pulmonary diseases caused by MOTT in childhood. In the present case, antituberculotic chemotherapy was modified due to sensitivity results, which led to clinical and radiological improvement. Surgery is the treatment of choice in cervical lymphadenopathy caused by MOTT. In MOTT diseases of the lung, thoracic surgery should be considered if chemotherapy fails.

In Germany, due to the low risk of infection with $\mathrm{M}$. tuberculosis and the, as yet, uncertain risk of infection with MOTT, the possibility of infection with MOTT should be taken into consideration if there are positive tuberculin skin test results (especially with high tuberculin concentrations) and corresponding radiographic alterations, but standard antituberculotic chemotherapy is not effective.

Despite its uncertain reliability, MOTT sensitin testing, could be helpful for diagnosis in some cases $[4,11]$. Bacteriological cultures are still the gold standard for detecting mycobacterial infections in childhood [12].

Keywords: Antituberculotic chemotherapy, bronchoscopy, children, M. avium, tuberculosis

\section{References}

1. Wolinsky E. Mycobacterial lymphadenitis in children: a prospective study of 105 nontuberculous cases with longterm follow-up. Clin Infect Dis 1995; 20: 954-963.

2. Gupta SK, Katz BZ. Intrathoracic disease associated with Mycobacterium avium-intracellulare complex in otherwise healthy children: diagnostic and therapeutic considerations. Pediatrics 1994; 94: 741-742.

3. Romanus V, Hallander HO, Wahlen P, Olinder-Nielsen AM, Magnusson PHW, Juhlin I. Atypical mycobacteria in extrapulmonary disease among children: incidence in Sweden from 1969 to 1990 , related to changing BCG vaccination coverage. Tubercle Lung Dis 1995; 76: 300-310. 
4. Magdorf K, Khouw I, Ertel M, Wahn U. Positiver Tuberkulintest bei nicht BCG-geimpften Kindern - immer ein Hinweis auf eine spezifische Infektion? Monatsschr Kinderheilkd 1996; 144: (in press).

5. Griffith DE, Wallace RJ. Environmental (nontuberculous) mycobacterial disease. Text Int Med 1992; 289: $1435-1438$.

6. Wallace RJ, O'Brien R, Glassroth J, Raleigh J, Dutt A. Diagnosis and treatment of disease caused by nontuberculous mycobacteria. Am Rev Respir Dis 1990; 142: 940-953.

7. Kinney JS, Little BJ, Yolken RH, Rosenstein BJ. Mycobacterium avium complex in a patient with cystic fibrosis: disease versus colonization. Pediatr Infect Dis J 1989; 8: 393-396.

8. Albertini M, Monpoux F, Blanche S, Sirvent N, Giudicelli $\mathrm{H}$, Mariani R. Infection pulmonaire probable à mycobacterie non tuberculeuse chez une enfant atteinte de granulomatose septique chronique. Ann Pediatr 1994; 41: 628-632.

9. Gleason-Morgan D, Church JA, Ross LA. A comparative study of transfusion-acquired human immunodeficiency virus-infected children with and without disseminated Mycobacterium avium complex. Pediatr Infect Dis J 1994; 13: 484-488.

10. Pierre C, Olivier C, Lecossier D, Boussougant Y, Yeni $\mathrm{P}$, Hance AJ. Diagnosis of primary tuberculosis in children by amplification and detection of mycobacterial DNA. Am Rev Respir Dis 1993; 147: 420-424.

11. Larsson LO, Magnusson M, Skoogh B-E, Lind A. Sensitivity to sensitins and tuberculin in Swedish children. IV. The influence of BCG vaccination. Eur Respir J 1992; 5: 584-586.

12. Magdorf K, Freihorst J, Wahn U, von der Hardt H. Kindertuberkulose in Deutschland. Med Klin 1995; 90 : 585-593. 